\title{
EVALUATION OF GASTROPROTECTIVE EFFECT OF COENZYME Q 10 AND L - GLUTAMINE IN STRESS AND ETHANOL-INDUCED PEPTIC ULCER IN WISTAR RATS: A NOVEL PRECLINICAL STUDY
}

\author{
BALAJI OMMURUGAN ${ }^{1}$, SHALINI ADIGA ${ }^{2 *}$, VIJETHA SHENOY BELLE ${ }^{2}$ \\ ${ }^{1}$ Department of Pharmacology, Kasturba Medical College, Manipal Academy of Higher Education, Manipal, Karnataka, India. ${ }^{2}$ Department of \\ Biochemistry, Kasturba Medical College, Manipal Academy of Higher Education, Manipal, Karnataka, India. Email: shalini.adiga@manipal.edu
}

Received: 13 March 2018, Revised and Accepted: 02 June 2018

\section{ABSTRACT}

Objective: Coenzyme Q 10 (CoQ10) and L-glutamine have antioxidant property their role in peptic ulcer diseases is not well known. Hence, the aim of present study is to evaluate the gastroprotective role of CoQ10 and L-glutamine in stress and ethanol-induced peptic ulcers in Wistar albino rats.

Methods: A total of 90 rats were used for the conduct of study in two experimental models, the stress- and the ethanol-induced ulcer model. Each model consists of eight groups with six rats in each group. Sucralfate and pantoprazole were used as standard drugs along with CoQ10 and L-glutamine as test drugs. Drugs were administered for 10 days in stress model and 7 days in case of ethanol model. Statistically analyzed using analysis of variance and post-hoc test with significance as $\mathrm{p}>0.05$

Results: CoQ10 and L- glutamine when used alone as well in combination with pantoprazole and sucralfate showed no ulcer formation. Test drugs showed decrease in gastric acid secretion, decreased total and free acidity levels, higher gastric $\mathrm{pH}$, increased mucous secreting ability, higher levels of reduced glutathione levels in both tissue as well as blood and lower malondialdehyde levels when compared with pantoprazole and sucralfate suggestive of their antioxidative benefit, in both the models.

Conclusion: Well-designed clinical trials can be done to evaluate the use of CoQ10 and L- glutamine in the treatment of peptic ulcer disease due to various etiology.

Keywords: Antioxidants, Alcohol, Stress, Proton pump inhibitors, Mucous coating agents.

(c) 2018 The Authors. Published by Innovare Academic Sciences Pvt Ltd. This is an open access article under the CC BY license (http://creativecommons. org/licenses/by/4. 0/) DOI: http://dx.doi.org/10.22159/ajpcr.2018.v11i9.25904

\section{INTRODUCTION}

Peptic ulcer is defined as a local defect or excavation on the surface of stomach with a mucosal break of diameter $5 \mathrm{~mm}$ or larger, usually produced by sloughing of the inflammatory necrotic tissue. Etiology of peptic ulcer is fiercely debated and is believed that peptic ulcers develop due to imbalance between aggressive factors (Helicobacter pylori, non-steroidal anti-inflammatory drugs (NSAIDs), gastric acid) and protective factors (mucin, bicarbonate, prostaglandins) leading to interruption of mucosal integrity [1]. Various factors are implicated to play a pivotal role in pathogenesis of ulceration such as sedentary lifestyle, alcohol, smoking, spicy food, physiological stress, drugs such as NSAIDs and various bacterial infections [1]. Oxidative stress has emerged as one of the major pathogenic factors in progression of ulcer as it directly impairs the cellular function and promote cellular organelle damage in mitochondria, lysosomes, and nucleus [2].

Stress-induced peptic ulcer is a pathological condition affecting the gastrointestinal tract. Stress ulcers are commonly found in the gastric mucosa anywhere within the stomach to duodenum. The pathogenesis is mainly due to reduction in mucosal blood flow or a break down in other normal mucosal defense mechanisms. Effective therapy remains elusive in the treatment of stress-induced peptic ulcers [3]. One of the common denominators for the occurrence of the disease is involvement of free radicals, an increase in histamine $\left(\mathrm{H}_{2}\right)$ release and decreased mucous production. Reactive oxygen species (ROS) are generated by various metabolic activities and antioxidant enzymes such as superoxide dismutase, catalase, lipid peroxidase, and glutathione peroxidase control their accumulation. Any imbalance in the activity of these enzymes leads to faulty disposal of free radical and their accumulation [4].
Alcoholis one of the leading causes of peptic ulcer disease. The mechanism of ethanol-induced gastric lesions is varied including the depletion of gastric mucus content, damaged mucosal blood flow and mucosal cell injury. It decreases bicarbonate and mucus production by which it produces necrotic lesion in gastric mucosa. Ethanol initiates apoptosis which leads to the cell death. It also releases superoxide dismutase and hydroperoxyl free radical species in the biological system [4].

Various drugs have been used to treat peptic ulcer disease such as proton pump inhibitors (PPIs), $\mathrm{H}_{2}$-receptor antagonists, prostaglandin analogs, and sucralfate. Because these drugs are complex, expensive and toxic, efforts have been constantly made to find a suitable, palliative, and curative agent for the treatment of peptic ulcer disease from natural products of plant and animal origin. Recently, antioxidants are being used to treat peptic ulcer disease. Antioxidants help in scavenging the free radicals and controlling the oxidative stress responsible for the progression of peptic ulcer [2]. Coenzyme Q 10 (CoQ10) and L-glutamine have antioxidant property, and their role as antioxidants has been documented in the literature in treating medical conditions [5,6]. Their role in peptic ulcer diseases is not well known with only few studies reporting the use of CoQ10 and L - glutamine in peptic ulcer treatment in animals and no human studies have been done so far $[7,8]$. Hence, the aim of present study is to evaluate the gastroprotective role of CoQ10 and L-glutamine in stress and ethanol-induced peptic ulcers in Wistar albino rats.

\section{MATERIALS AND METHODS}

Animals

Male/female albino rats of Wistar stain weighing 180-250 g and 10-12 weeks were used for the study. The animals were housed under 
standard condition, $12: 12$ light-dark cycle, $50 \%$ humidity and $28^{\circ} \mathrm{C}$ temperature and provided with standard food granules and water adlibitum. Institutional Ethical Committee Clearance (Kasturba Medical College $[\mathrm{KMC}] / 76 / 2015)$ was obtained before the start of the therapy.

\section{Drugs/chemicals/instruments}

L-glutamine, CoQ10 was purchased from Jarrow formula, USA. Pantoprazole and sucralfate were purchased from pharmacy stores, KMC, Manipal. Orcinol, phenolphthalein, Topfer's reagent, sulfuric acid, surgical kit, and suture material were used from departmental lab.

\section{Experimental design}

A total of 90 rats were used for the conduct of study in two experimental models, the stress and the ethanol-induced ulcer model. Each model consists of eight groups with six rats in each group. Group 1: Normal control rats given $1 \mathrm{ml}$ of $0.5 \%$ carboxymethylcellulose (same control for both model), Group 2: (Ulcer control), stress ulcer in case of stress ulcer model and $1 \mathrm{ml}$ ethanol in case of ethanol model, Group 3: Sucralfate $500 \mathrm{mg} / \mathrm{kg}$ (standard), Group 4: Pantoprazole $30 \mathrm{mg} / \mathrm{kg}$ (standard), Group 5: CoQ10 $400 \mathrm{mg} / \mathrm{kg}$ (test), Group 6: L-glutamine $1000 \mathrm{mg} / \mathrm{kg}$ (test), Group 7: CoQ10 plus L-glutamine plus sucralfate (test), and Group 8: CoQ10 plus L-glutamine plus pantoprazole (test). Drugs were administered orally with feeding needle once daily for 10 days in stress model and 7 days in case of ethanol model. All drugs were mixed with $0.5 \%$ carboxymethylcellulose and were administered. The dose of the drugs used in our study was obtained from previous studies in the literature [9-11].

\section{Study procedure \\ Stress ulcer model in rats}

This model employs the restraint technique developed by Brodie and Hanson coupled with cold-induced stress model by Levine [12]. The combination of these methods is proven to be synergistic in developing acute ulcers in rats arising mainly from physiological discomfort [12]. Brodie and Hanson used this method for production of restraint ulcers. Wistar rats of either sex weighing 200-250 g were housed in separate cages and divided into groups. The drugs were given for 10 days. After the last dose, animals were deprived of food for $36 \mathrm{~h}$ before experimentation. Each rat was then placed in a piece of galvanized steel window screen of appropriate size. The limbs were put together in pair and tightened with adhesive tapes so that the animal cannot move. They were placed in cages for $24 \mathrm{~h}$. After restraining the animals, they were subjected to temperature of $2-3^{\circ} \mathrm{C}$ for 2 to $4 \mathrm{~h}$ in ice-lined refrigerator as in case of cold-induced stress model. Animals were sacrificed using cervical dislocation, and macroscopic examination of stomach was done and other laboratory investigations were carried out. All animals were subjected to stress except for the vehicle control group which received only $0.5 \%$ Carboxymethyl cellulose.

\section{Ethanol induced ulcer model}

Wistar rats of either sex weighing 200-250 g were fasted for $24 \mathrm{~h}$. The drugs were given for 7 days. On $7^{\text {th }}$ day 30 min after drug administration $95 \%$ ethanol was given at a dose of $1 \mathrm{ml} / 200 \mathrm{~g}$. Animals were sacrificed by cervical dislocation an hour after ethanol administration [13]. The effect of the drugs given was analyzed.

\section{Laboratory assessment}

\section{Ulcer index measurement}

Animals were sacrificed by cervical dislocation, and a midline incision was made with the scalpel. The stomach was removed from the ligamentous attachments and was homogenized in $0.9 \%$ ice cold saline. After that stomach was dissected and cut open along the greater curvature. The gastric fluid was collected in a microtube. It was fixed on a board; examination was carried out with hand lens macroscopically. Tracing of ulcer border was done on the transparent paper and the paper was traced back on to graph sheets. Size of ulcers and the ulcer index was calculated using the formula, ulcer index $=$ ulcer size $\times$ ulcer number [14].

\section{Estimation of lipid peroxidation}

Malondialdehyde (MDA) measurement was done in both gastric tissue and serum. A volume of $2 \mathrm{ml}$ of blood was withdrawn from retroorbital plexus before sacrificing the animal. MDA, end products of lipid peroxidation, reacts with thiobarbituric acid to form a colored complex, a complex that has maximum absorbance at $532 \mathrm{~nm}$ [15].

\section{Estimation of glutathione reductase}

Glutathione reductase measurement was done in both gastric tissue and serum. A volume of $2 \mathrm{ml}$ of blood was withdrawn from retro-orbital plexus before sacrificing the animal. Glutathione was measured by its reaction with 5, 5'dithio 2-nitrobenzoic acid to give a compound that absorbs light at $412 \mathrm{~nm}[16]$.

\section{Mucin content determination}

Diluted sample of orcinol (1.6\%) and sulfuric acid $(60 \%)$ were added to gastric fluid sample after centrifugation, vortexed and boiled for $10 \mathrm{~min}$; mixtures were cooled in ice cold water to stop reaction and absorbance studied at $425 \mathrm{~nm}$ [17].

\section{Measurement of volume of gastric juice}

The animals were sacrificed, and gastric juice from the stomach was drained into a centrifuge tube and centrifuged at $3000 \mathrm{rpm}$ for $10 \mathrm{~min}$, and the final sample was decanted and analyzed for the volume of gastric juice [17].

\section{Measurement of $\mathbf{p H}$ of gastric juice}

$\mathrm{pH}$ of the centrifuged sample of gastric juice is measured using a digital pH meter, type DPH-100 (Dalal instruments).

\section{Measurement of free and total acidity}

The free and total acidity was measured by titrating $0.1 \mathrm{ml}$ of gastric juice with $0.01 \mathrm{~N} \mathrm{NaOH}$ using Topfer's reagent and phenolphthalein as indicators. Orange-yellow endpoint with topfer's reagent for the free acid content and the pink endpoint with phenolphthalein for total acid content was noted and acidity was calculated [18].

\section{Statistical analysis}

The data were analyzed using one-way analysis of variance followed by post-hoc analysis using Tukey's test in SPSS version 23.0 software. The level of statistical significance for any measure was set at $p<0.05$ at a confidence interval of $95 \%$. The data were expressed as mean \pm standard error mean.

\section{RESULTS}

Effect on ulcer size, ucler number, and ulcer index

In stress model, the morphological pictures of stomach ulcer observed among all eight groups are shown in Fig. 1. Ulcers were observed in ulcer control, sucralfate, and pantoprazole groups but test groups did not have any ulcers. Ulcer control group showed significant $(p<0.001)$ increase in ulcer size, number, and index when compared with all the other groups. All the test groups as well as the standard pantoprazole group showed significant $(\mathrm{p}<0.01)$ decrease in ulcer formation when compared with sucralfate treated group. Test groups did not show any significant $(p>0.05)$ difference in ulcer formation with respect to pantoprazole group (Table 1).

In ethanol ulcer model, the morphological pictures of stomach ulcer observed among all eight groups are shown in Fig. 2. Ulcers were observed in all groups except the vehicle control and the test groups. Ulcer control group showed significant $(\mathrm{p}<0.001)$ increase in ulcer size, number, and index when compared with all the other groups. Test groups did not show any statistically significant difference $(p>0.05)$ in ulcer formation and were comparable to the standard treatment groups (Table 2).

\section{Effect on mucin content}

In stress ulcer model, ulcer control group showed significant $(\mathrm{p}<0.001)$ decrease in mucin content when compared with all the other groups. Test 


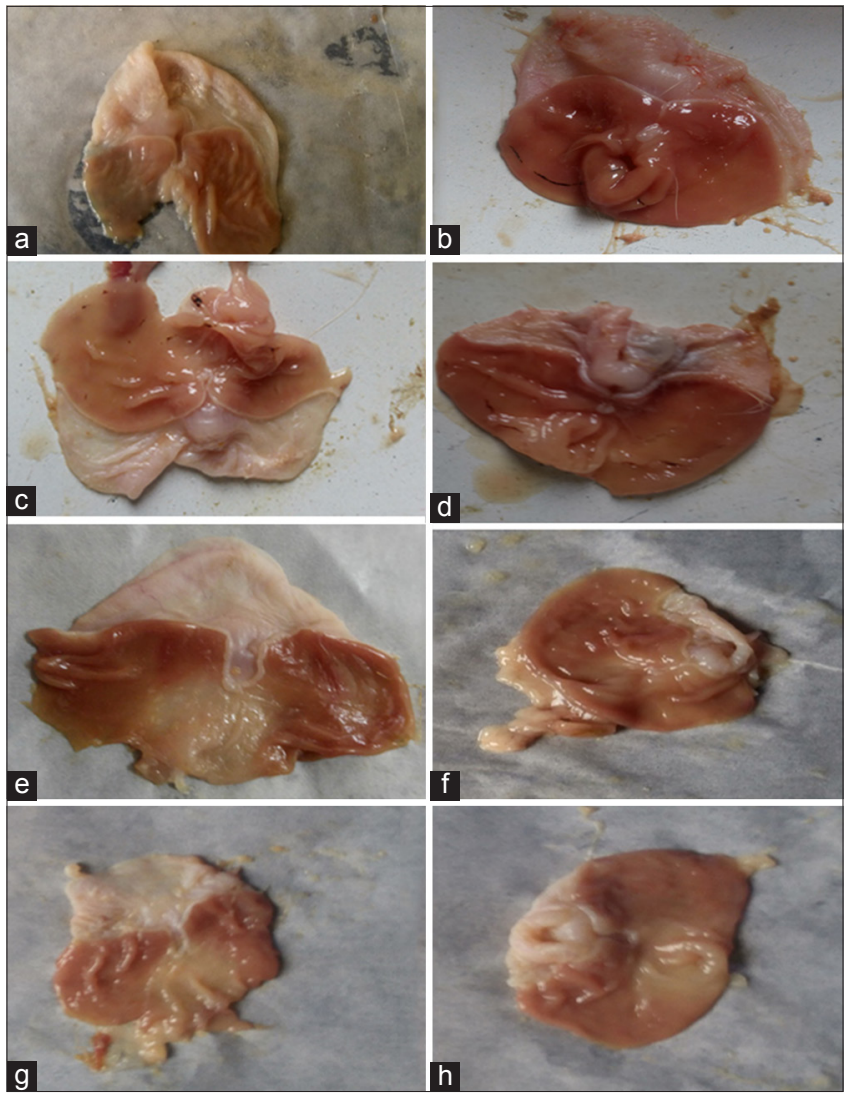

Fig. 1: Gross ulcers in stress model. (a) vehicle control, (b) ulcer control, (c) sucralfate, (d) pantoprazole, (e) Coenzyme Q 10 (CoQ10), (f) L-glutamine, (g) CoQ10+L-glutamine+sucralfate, (h) CoQ10+L-glutamine+pantoprazole

Table 1: Ulcer measurement stress model

\begin{tabular}{llll}
\hline Group n=6 & Mean \pm SEM & & \\
\cline { 2 - 4 } & $\begin{array}{l}\text { Mean ulcer size } \\
(\mathbf{m m})\end{array}$ & $\begin{array}{l}\text { Mean ulcer } \\
\text { number }\end{array}$ & $\begin{array}{l}\text { Mean ulcer } \\
\text { index }\end{array}$ \\
\hline Group 1 & 0 & 0 & 0 \\
Group 2 & $33.00 \pm 2.20^{*}$ & $4.6667 \pm 0.33^{*}$ & $152.3 \pm 11.0^{*}$ \\
Group 3 & $5.40 \pm 0.17$ & $8.5000 \pm 0.42$ & $46.23 \pm 3.72$ \\
Group 4 & $0.375 \pm 0.17^{* *}$ & $1.5000 \pm 0.71^{* *}$ & $1.16 \pm 0.64^{* *}$ \\
Group 5 & $0^{* *}$ & $0^{* *}$ & $0^{* *}$ \\
Group 6 & $0^{* *}$ & $0^{* *}$ & $0^{* *}$ \\
Group 7 & $0^{* *}$ & $0^{* *}$ & $0^{* *}$ \\
Group 8 & $0^{* *}$ & $0^{* *}$ & $0^{* *}$ \\
\hline
\end{tabular}

${ }^{*} \mathrm{p}<0.001$ : Group 2 versus all other groups, ${ }^{* *} \mathrm{p}<0.01$ : Group $4,5,6,7,8$ versus Group 3. Values were expressed as mean+SEM; one-way ANOVA was used to compare the means between the groups followed by Tukey's post-hoc analysis with $\mathrm{P}<0.05$ as statistically significant. SEM: Standard error mean, ANOVA: Analysis of variance

groups showed significant $(p<0.001)$ increase in mucin content when compared with both the standard drug-treated groups. Pantoprazole group showed significant $(\mathrm{p}<0.001)$ increase when compared with sucralfate treated group. The test groups and the vehicle control group were comparable without any significant difference in mucin content. There was no significant ( $p>0.05)$ difference in mucin content between the four test groups (Table 3).

In ethanol ulcer model, ulcer control group showed significant $(p<0.001)$ decrease in mucin content when compared with all the other groups. Test groups showed significant $(\mathrm{p}<0.001)$ increase in mucin content when compared with both the standard treatment groups. Pantoprazole treated group showed significant $(p<0.001)$ increase when compared with sucralfate treated group. There was no statistically significant $(p>0.05)$ difference and results were comparable between vehicle control and the test groups. There was no significant difference ( $p>0.050$ between the test groups (Table 4$)$.

\section{Effect on volume of gastric juice}

In stress ulcer model, ulcer control group showed significant $(\mathrm{p}<0.001)$ increase in gastric juice volume when compared with all the other groups. Test groups showed significant $(p<0.001)$ decrease in gastric juice volume when compared with sucralfate-treated group. The results of test groups were comparable to vehicle control and there was no difference in the gastric juice volume (Table 3)

In ethanol ulcer model, ulcer control group showed significant $(p<0.001)$ increase in gastric juice volume when compared with all the other groups. All test groups showed significant $(p<0.001)$ decrease in gastric juice volume when compared with standard treatment groups. Group 4 showed significant $(\mathrm{p}<0.001)$ decrease in gastric juice volume when compared with group 3 . There was no statistically significant $(p>0.05)$ difference in volume of gastric juice between test groups and vehicle control and results were comparable (Table 4).

\section{Effect on pH of gastric juice}

In stress ulcer model, ulcer control group showed significant $(p<0.001)$ reduction in $\mathrm{pH}$ when compared with all the other groups. Test groups showed significant $(\mathrm{p}<0.001)$ reduction in acidic $\mathrm{pH}$ when compared with sucralfate group. Test groups showed no significant ( $p>0.05$ ) difference in comparison with test pantoprazole group and results were comparable. Group 8 showed significant $(\mathrm{p}<0.001)$ reduction in acidic $\mathrm{pH}$ when compared with other test groups. The test groups were comparable to vehicle control animals (Table 3).

In ethanol ulcer model, ulcer control group showed significant $(\mathrm{p}<0.001)$ acidic $\mathrm{pH}$ when compared with all the other groups. All test groups showed significant $(\mathrm{p}<0.001)$ reduction in acidic $\mathrm{pH}$ when compared with Group 3. Group 7 and 8 showed significant $(\mathrm{p}<0.001)$ reduction in acidic $\mathrm{pH}$ when compared with 4 . There was no significant ( $>0.05$ ) difference between Group 1 and Groups 4, 5, 6 and 7, results were comparable. Group 8 showed significant $(\mathrm{p}<0.001)$ higher $\mathrm{pH}$ when compared with Group 1 (Table 4).

\section{Effect on free acidity}

In stress ulcer model, ulcer control group showed significant $(\mathrm{p}<0.001)$ increase in free acidity when compared with all the other groups. Test groups showed significant $(\mathrm{p}<0.001)$ decrease in free acidity when compared with sucralfate-treated group. Test groups showed results, comparable to vehicle control with no statistical significance. There was no significant $(p>0.05)$ difference between pantoprazole-treated groups and the test groups (Table 5).

In ethanol model, ulcer control group showed significant $(p<0.001)$ increase in free acidity when compared with all the other groups. Group 5, 6, 7, and 8 showed significant $(\mathrm{p}<0.001)$ reduced acidity when compared with Group 3. There was no significant $(p>0.05)$ difference in free acidity between test groups and vehicle control and results were comparable (Table 6)

\section{Effect on total acidity}

Group 2 showed significant $(\mathrm{p}<0.001)$ increase in total acidity when compared with all the other groups. Test groups showed significant $(p<0.001)$ increase in total acidity when compared with both the standard treatment groups. There was no significant $(p>0.05)$ difference between test groups (Table 5).

In ethanol ulcer model, ulcer control group showed significant $(p<0.001)$ increase in total acidity when compared with all the other groups. Test groups showed significant $(p<0.001)$ decrease in total 

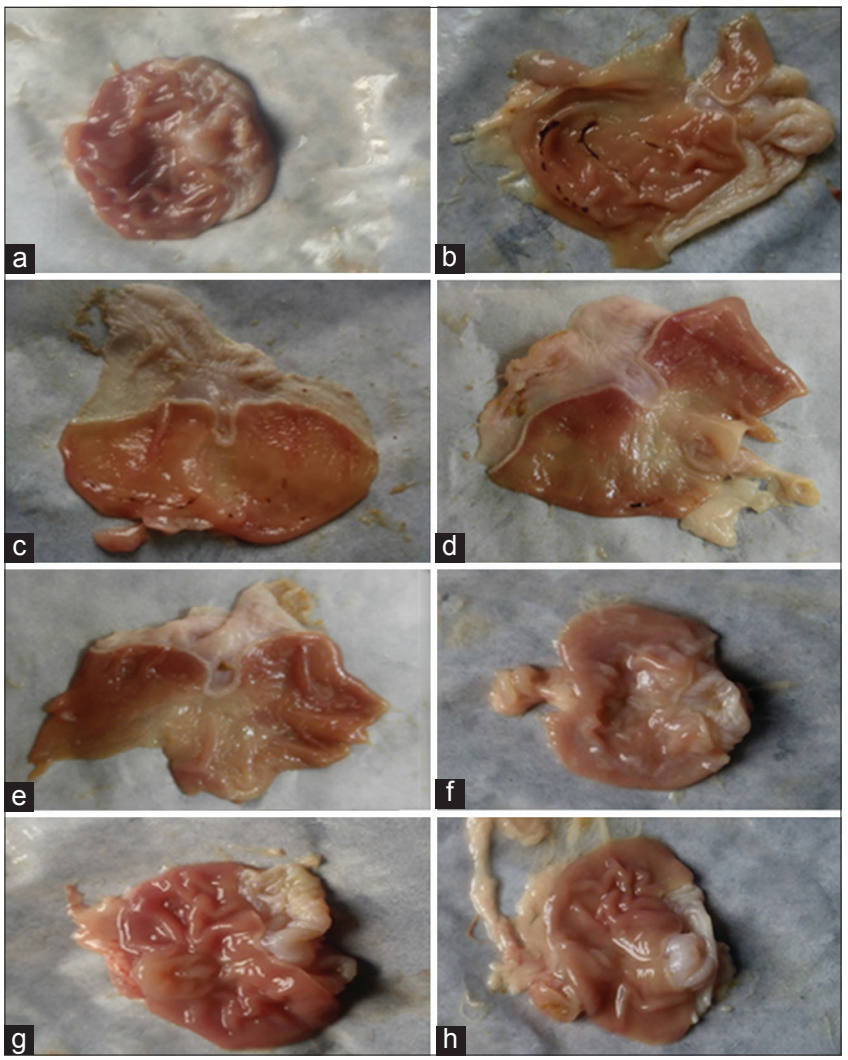

Fig. 2: Gross ulcers in ethanol model. (a) Vehicle control, (b) ulcer control, (c) sucralfate, (d) pantoprazole, (e) Coenzyme Q 10 (CoQ10), (f) L-glutamine, (g) CoQ10+L-glutamine+sucralfate (h) COQ10+l-glutamine+pantoprazole

Table 2: Ulcer measurement ethanol model

\begin{tabular}{llll}
\hline Group n=6 & Mean \pm SEM & & \\
\cline { 2 - 4 } & $\begin{array}{l}\text { Mean ulcer size } \\
(\mathbf{m m})\end{array}$ & $\begin{array}{l}\text { Mean ulcer } \\
\text { number }\end{array}$ & $\begin{array}{l}\text { Mean ulcer } \\
\text { index }\end{array}$ \\
\hline Group 1 & 0 & 0 & 0 \\
Group 2 & $62.5000 \pm 2.48^{*}$ & $10.3333 \pm 0.43^{*}$ & $650.8 \pm 43.0^{*}$ \\
Group 3 & $4.750 \pm 0.62$ & $7.5000 \pm 1.50$ & $39.83 \pm 9.89$ \\
Group 4 & $1.1250 \pm 0.36$ & $0.8333 \pm 0.30$ & $1.37 \pm 0.48$ \\
Group 5 & 0 & 0 & 0 \\
Group 6 & 0 & 0 & 0 \\
Group 7 & 0 & 0 & 0 \\
Group 8 & 0 & 0 & 0 \\
\hline
\end{tabular}

${ }^{*} \mathrm{p}<0.001$ : Group 2 versus all other groups. Values were expressed as mean \pm SEM, one-way ANOVA was used to compare the means between the groups followed by Tukey's post-hoc analysis with $\mathrm{P}<0.05$ as statistically significant. SEM: Standard error mean, ANOVA: Analysis of variance

acidity when compared with standard treatment groups. There was no statistically significant ( $p>0.05$ ) difference between the test groups (Table 6).

\section{Antioxidant status in blood and gastric tissue}

In both stress and ethanol-induced ulcer models, ulcer control group showed significant $(\mathrm{p}<0.001)$ increase in tissue as well as blood MDA levels when compared with all the other groups. Test groups showed significant $(\mathrm{p}<0.001)$ decrease in tissue as well as blood MDA levels when compared with sucralfate and pantoprazole. Pantoprazoletreated group showed significant $(\mathrm{p}<0.001)$ decrease in tissue as well as blood MDA levels as compared to sucralfate treated group. There was no significant ( $p>0.05$ ) difference between the test groups (Tables 7 and 8).
Table 3: Estimation of $\mathrm{pH}$, mucin content, and volume of gastric juice - stress model

\begin{tabular}{llll}
\hline $\begin{array}{l}\text { Groups (stress) } \\
\mathbf{n}=\mathbf{6}\end{array}$ & mean \pm SEM & & \\
\cline { 2 - 4 } & $\mathbf{p H}$ & $\begin{array}{l}\text { Volume } \\
(\mathbf{m l} / \mathbf{1 0 0} \mathbf{g})\end{array}$ & $\begin{array}{l}\text { Mucin content } \\
(\boldsymbol{\mu} \mathbf{g} / \mathbf{m l})\end{array}$ \\
\hline Group 1 & $4.93 \pm 0.01$ & $2.62 \pm 0.09$ & $368.6 \pm 0.89$ \\
Group 2 & $3.15 \pm 0.09^{*}$ & $7.64 \pm 0.32^{*}$ & $159.8 \pm 6.77^{*}$ \\
Group 3 & $4.44 \pm 0.09$ & $4.94 \pm 0.11$ & $197.3 \pm 3.56$ \\
Group 4 & $4.99 \pm 0.03^{* * *}$ & $2.80 \pm 0.19^{* * *}$ & $316.4 \pm 7.81^{* * *}$ \\
Group 5 & $5.10 \pm 0.03^{* *}$ & $2.30 \pm 0.06^{* *}$ & $359.7 \pm 3.51^{* *}$ \\
Group 6 & $5.12 \pm 0.02^{* *}$ & $2.29 \pm 0.05^{* *}$ & $360.1 \pm 2.5^{* *}$ \\
Group 7 & $5.11 \pm 0.02^{* *}$ & $2.30 \pm 0.04^{* *}$ & $361.8 \pm 1.73^{* *}$ \\
Group 8 & $5.67 \pm 0.04 \$^{* *}$ & $2.25 \pm 0.04^{* *}$ & $378.1 \pm 3.37^{* *}$ \\
\hline
\end{tabular}

${ }^{*} \mathrm{p}<0.001$ : Group 2 versus all other groups, ${ }^{* *} \mathrm{p}<0.001$ : Group $5,6,7,8$ versus $3,4 .{ }^{* * *} \mathrm{p}<0.001$ : Group 4 versus Group $3,{ }^{\$} \mathrm{p}<0.001$ : Group 8 versus 5, 6, 7 . Values were expressed as mean \pm SEM; one-way ANOVA was used to compare the means between the groups followed by Tukey's post-hoc analysis with $\mathrm{P}<0.05$ as statistically significant. SEM: Standard error mean, ANOVA: Analysis of variance

Table 4: Estimation of $\mathrm{pH}$, mucin content and volume of gastric juice - ethanol model

\begin{tabular}{llll}
\hline $\begin{array}{l}\text { Groups } \\
\mathbf{n}=6\end{array}$ & $\mathbf{p H}($ mean \pm SEM) & $\begin{array}{l}\text { Volume } \\
(\mathbf{m l} / \mathbf{1 0 0} \mathbf{g}) \\
(\mathbf{m e a n} \pm \text { SEM) }\end{array}$ & $\begin{array}{l}\text { Mucin } \\
\text { content }(\boldsymbol{\mu g} / \mathbf{m l}) \\
\text { (mean } \pm \text { SEM) }\end{array}$ \\
\hline Group 1 & $4.93 \pm 0.01$ & $2.62 \pm 0.24$ & $368.6 \pm 0.89$ \\
Group 2 & $2.15 \pm 0.09^{*}$ & $7.97 \pm 0.30^{*}$ & $120.9 \pm 5.84^{*}$ \\
Group 3 & $3.59 \pm 0.11$ & $5.57 \pm 0.31$ & $226.7 \pm 5.46$ \\
Group 4 & $4.88 \pm 0.03^{* *}$ & $4.58 \pm 0.26 \#$ & $320.5 \pm 6.84 \#$ \\
Group 5 & $5.13 \pm 0.04^{* *}$ & $2.52 \pm 0.16^{* * *}$ & $366.9 \pm 1.52^{* * *}$ \\
Group 6 & $5.18 \pm 0.06^{* *}$ & $2.59 \pm 0.19^{* * *}$ & $379.6 \pm 3.00^{* * *}$ \\
Group 7 & $5.28 \pm 0.05^{\wedge * *}$ & $2.59 \pm 0.22^{* * *}$ & $368.3 \pm 4.20^{* * *}$ \\
Group 8 & $5.44 \pm 0.12^{\wedge} \$^{* *}$ & $2.39 \pm 0.33^{* * *}$ & $381.8 \pm 1.97^{* * *}$ \\
\hline
\end{tabular}

${ }^{*} \mathrm{p}<0.001$ : Group 2 versus all other groups, ${ }^{* *} \mathrm{p}<0.001$ : Group $4,5,6,7,8$ versus Group 3. ${ }^{* *} \mathrm{p}<0.001$ : Group 5, 6, 7, 8 versus $3,4,{ }^{\wedge} \mathrm{p}<0.001$ : Group 7, 8 versus 4 ${ }^{\$} \mathrm{p}<0.001$ : Group 8 versus Groups 1, $\mathrm{p}<00.001$ : Group 4 versus Group 3. Values were expressed as mean \pm SEM, one-way ANOVA was used to compare the means between the groups followed by Tukey's post-hoc analysis with $\mathrm{P}<0.05$ as statistically significant. SEM: Standard error mean, ANOVA: Analysis of variance

In both stress- and ethanol-induced ulcer models, ulcer control showed significant $(\mathrm{p}<0.001)$ decrease in tissue as well as blood reduced glutathione (GSH) levels when compared with all the other groups. Test groups showed significant $(\mathrm{p}<0.001)$ increase in tissue as well as blood GSH levels when compared with both the standard treatment groups. Pantoprazole-treated group showed significant $(\mathrm{p}<0.001)$ increase in tissue as well as blood GSH levels when compared with sucralfate treated group. There was no significant $(p>0.05)$ difference between the test groups and they were comparable to the vehicle control (Tables 7 and 8).

\section{DISCUSSION}

In our study, the ulcers produced with ethanol model were similar to those observed in previous studies, where a single dose of $1 \mathrm{ml} / 200 \mathrm{~g}$ of $95 \%$ alcohol, produced gastric ulcers within $1 \mathrm{~h}$. The main mechanism of gastric ulcer after ingestion of $95 \%$ alcohol single dose are mainly due to cellular necrosis and the release of free radical as ethanol gets metabolized in the body. There is a severe reduction in the gastric mucosal blood flow resulting in gastric injury. Besides prostaglandins, L-arginine/nitric oxide (NO) pathway causes relaxation of the arterial smooth muscles. Vasodilation of gastric blood vessels helps in preventing the gastric injury by enhancing the mucosal integrity. However, ethanol alters these mechanisms and disorganizes the gastric mucosal surfactants thereby leading to ulcer [19-22].

PPIs and sucralfate are the preferred drugs in the treatment of alcohol-induced peptic ulcer disease. Various animal studies have 
Table 5: Estimation of free and total acidity of gastric fluid - stress model

\begin{tabular}{lll}
\hline $\begin{array}{l}\text { Groups } \\
\mathbf{n = 6}\end{array}$ & $\begin{array}{l}\text { Free acidity } \\
\text { (meq/l/100 g) }\end{array}$ & $\begin{array}{l}\text { Total acidity } \\
\text { (meq/l/100 g) }\end{array}$ \\
\hline Group 1 & $6.04 \pm 0.05$ & $21.51 \pm 0.87$ \\
Group 2 & $32.19 \pm 2.7^{*}$ & $72.71 \pm 0.81^{*}$ \\
Group 3 & $7.63 \pm 0.16$ & $47.55 \pm 1.06$ \\
Group 4 & $6.40 \pm 0.16$ & $28.70 \pm 0.16$ \\
Group 5 & $5.65 \pm 0.08^{* *}$ & $22.81 \pm 0.08^{* * *}$ \\
Group 6 & $5.57 \pm 0.09^{* *}$ & $22.53 \pm 0.09^{* * *}$ \\
Group 7 & $5.39 \pm 0.10^{* *}$ & $21.80 \pm 0.10^{* * *}$ \\
Group 8 & $5.21 \pm 0.10^{* *}$ & $19.87 \pm 0.10^{* * *}$ \\
\hline
\end{tabular}

${ }^{*} \mathrm{p}<0.001$ : Group 2 versus all other groups, ${ }^{* *} \mathrm{p}<0.001$ : Groups 5, 6, 7, 8 versus Group 3, ${ }^{* *}$ p $<0.001$ : Group 5, 6, 7, 8 versus 3, 4. Values were expressed as mean \pm SEM, one-way ANOVA was used to compare the means between the groups followed by Tukey's post-hoc analysis with $\mathrm{P}<0.05$ as statistically significant. SEM: Standard error mean, ANOVA: Analysis of variance

Table 6: Estimation of free and total acidity of gastric fluid - ethanol model

\begin{tabular}{lll}
\hline Groups n=6 & $\begin{array}{l}\text { Free acidity } \\
\text { (mEq/L/100 g) }\end{array}$ & $\begin{array}{l}\text { Total acidity } \\
\text { (mEq/L/100 g) }\end{array}$ \\
\hline Group 1 & $6.03 \pm 0.04$ & $21.51 \pm 0.87$ \\
Group 2 & $28.35 \pm 1.02^{*}$ & $82.88 \pm 0.74^{*}$ \\
Group 3 & $8.77 \pm 0.14$ & $43.12 \pm 1.08$ \\
Group 4 & $7.61 \pm 0.11$ & $34.58 \pm 1.45^{* * *}$ \\
Group 5 & $6.02 \pm 0.07^{* *}$ & $22.76 \pm 1.41^{* * *}$ \\
Group 6 & $5.92 \pm 0.05^{* *}$ & $21.56 \pm 0.96^{* * *}$ \\
Group 7 & $6.02 \pm 0.10^{* *}$ & $19.98 \pm 0.93^{* * *}$ \\
Group 8 & $5.86 \pm 0.13^{* *}$ & $18.73 \pm 0.78^{* * *}$ \\
\hline
\end{tabular}

${ }^{*} \mathrm{p}<0.001$ : Group 2 versus all other groups, ${ }^{* *} \mathrm{p}<0.001$ : Groups $5,6,7,8$ versus Group 3. ${ }^{* *} p<0.001$ : Group 5, 6, 7, 8 versus 3, 4. Values were expressed as mean \pm SEM, one-way ANOVA was used to compare the means between the groups followed by Tukey's post-hoc analysis with $\mathrm{P}<0.05$ as statistically significant. SEM: Standard error mean, ANOVA: Analysis of variance shown these drugs to be successful. Our results are also similar to results obtained in previous studies [23,24]. In our study, pantoprazole showed more significant gastric protection when compared to sucralfate. The mechanism attributed to its efficacy is inhibition of acid secretion directly by inhibiting the proton pump which is the last step in the gastric acid secretion as compared to sucralfate which just coats the stomach and helps in preventing the acid to meet the mucosal layer and thereby prevents cellular necrosis and mucosal barrier damage [23,24].

We noted that CoQ10 group had no ulcer formation and its efficacy was better than pantoprazole and sucralfate. There is only one preclinical study reporting the use of CoQ10 on ethanol-induced ulcer in rats [8]. The results of that study showed that CoQ10 when used in combination with famotidine had better gastric protection. The study also revealed single dose of CoQ10 was not useful and multiple doses are required to achieve therapeutic concentrations in gastric tissue [8]. In another study, CoQ10 at high dose was used in indomethacin-induced gastric ulcers in rats and was found to have good gastric protection [9]. Similar observations were made in the present study. CoQ10 used alone in high doses of $400 \mathrm{mg}$ for 7 days did not show ulcer formation. The prevention of ulcer formation can be attributed to significant therapeutic concentrations obtained in gastric tissues with high doses. Nevertheless, the gastroprotective effect of CoQ10 has not been clarified up to date. Possible mechanisms of gastroprotection attributed to the CoQ10 are protection of biological membranes against oxidative stress, counterbalancing the overproduction of ROS by the metabolism of ethanol and counteracting the vasoconstriction due to impaired NO production by endothelium. In addition, CoQ10 maintains gastric mucus thickness to protect against acid attack [25-27].

In cold restraint stress model, ulcers produced were similar to those obtained in the previous animal studies. The mechanism by which ulcers are produced include $\mathrm{H}_{2}$ secretion leading to increase in acid secretion, decreased mucus production, and diminished gastric blood flow. Stress also reduces mucus production as well increases the

Table 7: Estimation of MDA and GSH levels in tissue and blood - stress model

\begin{tabular}{|c|c|c|c|c|}
\hline $\begin{array}{l}\text { Group } \\
n=6\end{array}$ & $\begin{array}{l}\text { Tissue MDA level } \\
(\mu \mathrm{mol} / \mathrm{mg})\end{array}$ & $\begin{array}{l}\text { Tissue GSH level } \\
(\mu \mathrm{mol} / \mathrm{mg})\end{array}$ & $\begin{array}{l}\text { Blood MDA levels } \\
(\mu \mathrm{mol} / \mathrm{mg})\end{array}$ & $\begin{array}{l}\text { Blood GSH levels } \\
\text { ( } \mu \mathrm{mol} / \mathrm{mg})\end{array}$ \\
\hline Group 1 & $0.008 \pm 0.00$ & $0.026 \pm 0.00$ & $0.007 \pm 0.00$ & $0.025 \pm 0.00$ \\
\hline Group 2 & $0.029 \pm 0.00^{*}$ & $0.009 \pm 0.00^{*}$ & $0.030 \pm 0.00^{*}$ & $0.009 \pm 0.00^{*}$ \\
\hline Group 3 & $0.020 \pm 0.00$ & $0.016 \pm 0.00$ & $0.020 \pm 0.00$ & $0.016 \pm 0.01$ \\
\hline Group 4 & $0.015 \pm 0.00^{* * *}$ & $0.020 \pm 0.00^{* * *}$ & $0.016 \pm 0.00^{* * *}$ & $0.018 \pm 0.01^{* * *}$ \\
\hline Group 5 & $0.009 \pm 0.00 * *$ & $0.021 \pm 0.00^{* *}$ & $0.008 \pm 0.00^{* *}$ & $0.021 \pm 0.01^{* *}$ \\
\hline Group 6 & $0.009 \pm 0.00^{* *}$ & $0.023 \pm 0.00^{* *}$ & $0.008 \pm 0.00^{* *}$ & $0.023 \pm 0.01^{* *}$ \\
\hline Group 8 & $0.007 \pm 0.01^{* *}$ & $0.028 \pm 0.00^{* *}$ & $0.006 \pm 0.00^{* *}$ & $0.027 \pm 0.01^{* *}$ \\
\hline
\end{tabular}

${ }^{*} \mathrm{p}<0.001$ : Group 2 versus all other groups, ${ }^{* *} \mathrm{p}<0.001$ : Group 5, 6, 7, 8 versus Group 3, 4. ${ }^{* * *} \mathrm{p}<0.001$ : Group 4 versus Groups 3 . Values were expressed as mean \pm SEM, one-way ANOVA was used to compare the means between the groups followed by Tukey's post-hoc analysis with $\mathrm{P}<0.05$ as statistically significant. MDA: Malondialdehyde, GSH: Reduced glutathione, SEM: Standard error mean, ANOVA: Analysis of variance

Table 8: Estimation of MDA and GSH levels in tissue and blood ethanol model

\begin{tabular}{llll}
\hline Group n=6 & $\begin{array}{l}\text { Tissue MDA level } \\
(\mu \mathrm{MOL} / \mathrm{MG})\end{array}$ & $\begin{array}{l}\text { Tissue GSH level } \\
(\boldsymbol{\mu M O L} / \mathbf{M G})\end{array}$ & $\begin{array}{l}\text { Blood MDA levels } \\
(\boldsymbol{\mu M O L} / \mathbf{M G})\end{array}$ \\
\hline Group 1 & $0.008 \pm 0.00$ & $0.026 \pm 0.00$ & $0.007 \pm 0.00$ \\
Group 2 & $0.027 \pm 0.02^{*}$ & $0.006 \pm 0.00^{*}$ & $0.029 \pm 0.00^{*}$ \\
Group 3 & $0.021 \pm 0.19$ & $0.019 \pm 0.00$ & $0.020 \pm 0.00$ \\
Group 4 & $0.015 \pm 0.01^{* * *}$ & $0.021 \pm 0.00^{* * *}$ & $0.015 \pm 0.00^{* * *}$ \\
Group 5 & $0.012 \pm 0.01^{* *}$ & $0.022 \pm 0.00^{* *}$ & $0.011 \pm 0.00^{* *}$ \\
Group 6 & $0.007 \pm 0.00^{* *}$ & $0.025 \pm 0.00^{* *}$ & $0.008 \pm 0.00^{* *}$ \\
Group 7 & $0.008 \pm 0.00^{* *}$ & $0.024 \pm 0.00^{* *}$ & $0.000 \pm \pm 0.00^{*}$ \\
Group 8 & $0.006 \pm 0.00^{* *}$ & $0.027 \pm 0.00^{* *}$ & $0.021 \pm 0.01$ \\
\hline
\end{tabular}

${ }^{*} \mathrm{p}<0.001$ : Group 2 versus all other groups, ${ }^{* *} \mathrm{p}<0.001$ : Group 5, 6, 7, 8 versus Group 3, 4. ${ }^{* * *} \mathrm{p}<0.001$ : Group 4 versus Groups 3. Values were expressed as

mean \pm SEM, one-way ANOVA was used to compare the means between the groups followed by Tukey's post-hoc analysis with $\mathrm{P}<0.05$ as statistically significant,

MDA: Malondialdehyde, GSH: Reduced glutathione, SEM: Standard error mean, ANOVA: Analysis of variance 
gastrointestinal motility which makes stomach folds to come in contact with acid at a higher rate. Translation, acylation, and glycosylation of the ribosomal peptides of mucus are also affected. Increased vagal activity is also known to contribute to increased acid secretion. The most important mechanism is the generation of ROS in case of restraint ulcer model, which reduce the levels of endogenous antioxidants such as tocopherol, GSH, ascorbic acid making mucosa more prone for oxidative damage. It also causes ulcer formation by increasing the lipid peroxidation [28,29].

In stress ulcer model, pantoprazole and sucralfate, produced effective gastroprotection and the results obtained were similar to previous studies in literature $[23,24]$. It was also observed that pantoprazole was more effective than sucralfate in preventing stress-induced gastric lesions. This was the first study carried out to evaluate the effect of CoQ10 in stress ulcers in rats and results showed it to be more effective than pantoprazole and sucralfate. High doses of CoQ10 were used for a period of 10 days to prevent stress ulcers. The mechanism by which CoQ10 protects against gastric ulcer caused by stress is mainly through its antioxidant effect [25-27].

In both the models, L-glutamine showed very effective gastric protection and was more effective than pantoprazole and sucralfate. It was also observed that L-glutamine was equally efficacious to CoQ10 in preventing gastric lesions. To the best of our knowledge, the protective role of L-glutamine has not been investigated so far and this is the first study to assess the protective role of L- glutamine in stress and ethanol-induced ulcers. As per literature evidence, one study reported the use of L-glutamine in aspirin-induced ulcers in rats and it showed that L-glutamine has no protective role in preventing gastric ulcer caused by aspirin in rats without pylorus ligation [10]. Recently, one study evaluated the use of L-glutamine and cimetidine in combination and showed that both these drugs used in combination had higher gastroprotective effect rather when used alone [30]. It opined that the ulcer protective activity of L-glutamine is mainly due to antioxidant property causing reduction in ROS and not because of antisecretory property as there were no significant changes in the gastric juice parameters [30]. However, the results obtained in our study were contradictory proving the significant antisecretory activity and the antioxidant property of L-glutamine when used in dose of $1000 \mathrm{mg} / \mathrm{kg}$. Hence, this shows that L-glutamine can be used as a single agent in preventing gastric ulcers induced by alcohol and stress.

\section{CONCLUSION}

So, CoQ10 and L-glutamine can be potential anti-ulcerative agents in the treatment of the peptic ulcer disease owing to their anti-secretory as well as their antioxidant property. Well-designed clinical trials need to be conducted in future to elucidate the potential benefits of these drugs in the treatment of peptic ulcer disease with various etiology. Proper pharmacokinetic and pharmacodynamic studies can be done to find out the dose required to treat peptic ulcer and to know the drugdrug interactions when used in combination with standard drugs such as PPIs, $\mathrm{H}_{2}$ antagonists and mucosal coating agents. The role of these agents in the treatment of $H$. pylori induced ulcers can also be explored along with standard regimens.

\section{ACKNOWLEDGMENT}

The authors would like to thank the Department of Pharmacology for providing support to carry out laboratory investigations. The authors would like to thank Department of biochemistry, KMC, Manipal and postgraduates from the department for helping me do laboratory investigations and also thank to Dr. Amod tilak for helping me in animal house and to Dr. Amita Priya.

\section{CONFLICT OF INTEREST}

\section{REFERENCES}

1. Prabhu V, Shivani A. An overview of history, pathogenesis and treatment of perforated peptic ulcer disease with evaluation of prognostic scoring in adults. Ann Med Health Sci Res 2014;4:22-9.

2. Tandon R, Khanna RD, Dorababu M, Goel RK. Oxidative stress and antioxidants status in peptic ulcer and gastric carcinoma. Indian $\mathrm{J}$ Physiol Pharm 2004;48:115-8.

3. Das D, Bandyopadhyay D, Bhattacharjee M, Banerjee RK. Hydroxyl radical is the major causative factor in stress-induced gastric ulceration. Free Radic Biol Med 1997;23:8-18.

4. Ko JK, Cho CH. Alcohol drinking and cigarette smoking: A" partner" for gastric ulceration. Chin Med J 2000;63:845-54.

5. Denny N, Chapple IL, Matthews JB. Antioxidant, and anti-inflammatory effects of coenzyme Q10: A preliminary study. J Dent Res 1999;78:8.

6. Heyland DK, Elke G, Cook D, Berger MM, Wischmeyer PE, Albert M, et al. Glutamine and antioxidants in the critically ill patient: A post hoc analysis of a large-scale randomized trial. JPEN J Parenter Enteral Nutr 2015;39:401-9.

7. Okabe S, Ohtsu K, Takeuch K, Takhal K. Effect of L -glutamine on indomethacin induced gastric lesions in the rat. Jpn J Pharm 1974:24;169-71.

8. Karkaya K, Barut F, Hanci V, Can M, Comert M, Ucan HB, et al. Gastro protective effects of CoQ10 on ethanol-induced acute gastric lesions. Bratisl Lek Listy 2015;116:51-6.

9. Malash AM, Abdallah DM, Agha AM, Kenawy SA. Gastro protective efficacy of coenzyme Q10 in indomethacin-induced gastropathy: Other potential mechanisms. Ulcers 2012;2012:6.

10. Okabe S, Takeuchi K, Nakamura K, Takagi K. Inhibitory effects of L-glutamine on the aspirin-induced gastric lesions in the rat. J Pharm Pharm 1974;26:605-11.

11. Alhan E, Küçüktülü U, Çalik A, Cinel A. Effect of sucralfate on gastric emptying and mucus under stress in rats. Isr J Med Sci 1995;31:356-9.

12. Levine RJ. A method for rapid production of stress ulcers in rats. In: Peptic Ulcer. Copenhagen: Munksgaard; 1971. p. 92-7.

13. Oates PJ, Hakkinen JP. Studies on the mechanism of ethanol-induced gastric damage in rats. Gastroenterology 1988;94:10-21.

14. Rao CM, Ramesh KU, Bairy KL, Kulkarni OR. Zinc complexes of NSAIDs abolish gastric ulceration propensity of parent drugs. Indian Drugs 1990;28:64-7.

15. Yagi K. Assay for serum lipid peroxide level and is clinical significance. New York: New York Academic Press; 1982. p. 223-42.

16. Pasupathi P, Saravan G, chinnaswamy P, Bhakthavathsalam G. Glutathione dependent enzymes and antioxidant status in gastric carcinoma patients. J Biomed 2009;7:101-9.

17. Khayyal MT, El-Ghazaly MA, Kenawy SA, Seif-El-Nasr M, Mahran LG, Kafafi YA. Antiulcerogenic effect of some gastrointestinally acting plant extracts and their combination. Arzneimittelforschung 2001;51:545-53.

18. Anoop A, Jegadeesan M. Biochemical studies on the anti-ulcer genic potential of Hemidesmus indicus R. Br. var. indicus. J Ethnopharmacol 2003;84:149-56.

19. Cho CH, Pfeiffer CJ, Misra HP. Ulcerogenic mechanism of ethanol and the action of sulphonyl fluoride on the rat stomach in-vivo. J Pharm Pharmacol 1991;43:495-8.

20. Szabo S, Trier JS, Brown A, Schnoor J, Homan HD, Bradford JC. A quantitative method for assessing the extent of experimental gastric erosions and ulcers. J Pharmacol Methods 1985;13:59-66.

21. Wallace JL, Miller MJ. Nitric oxide in mucosal defense: A little goes a long way. Gastroenterology 2000;119:512-20.

22. Mosnier P, Rayssiguier Y, Motta C, Pelissier E, Bommelaer G. Effect of ethanol on rat gastric surfactant: A fluorescence polarization study. Gastroenterology 1993;104:179-84.

23. Bae DK, Park D, Lee SH, Yang G, Yang YH, Kim TK, et al. Different antiulcer activities of pantoprazole in stress, alcohol and pylorus ligation-induced ulcer models. Lab Anim Res 2011;27:47-52.

24. Hollander D, Tarnawski A, Krause WJ, Gergely H. Protective effect of sucralfate against alcohol-induced gastric mucosal injury in the rat: Macroscopic, histologic, ultrastructural, and functional time sequence analysis. Gastroenterology 1985;88:366-74.

25. Jones K, Hughes K, Mischley L, McKenna DJ. Coenzyme Q-10: Efficacy, safety, and use. Altern Ther Health Med 2002;8:42-55.

26. Folkers K, Brown R, Judy WV, Morita M. Survival of cancer patients on therapy with coenzyme Q10. Biochem Biophys Res Commun 1993; $192: 241-5$

27. Rosenfeldt FL, Haas SJ, Krum H, Hadj A, Ng K, Leong JY, et al. 
Coenzyme Q10 in the treatment of hypertension: Meta-analysis of the clinical trials. J Hum Hypertens 2007;21:297-306.

28. Brodie DA, Hanson HM. A study of the factors involved in the production of gastric ulcers by the restraint technique. Gastroenterology 1960;38:353-60.

29. Kitagawa H, Fujiwara M, Osumi Y. Effects of water-immersion stress on gastric secretion and mucosal blood flow in rats. Gastroenterology 1979;77:298-302.

30. Okpo SO, Akinrinde S, Ottih AE, Anazodo U, Chijioke MC. Evaluation of gastro protective efficacy and safety profile of low dose cimetidine and 1-glutamine using gastric and duodenal ulcer models in rats. Afr J Pharm Res Develop 2016;8:44-5. 